\title{
Interaction of Glucosyltransferase from Streptococcus mutans with Various Glucans
}

\author{
By SHIGEYUKI HAMADA AND MITSUO TORII \\ Department of Oral Microbiology, Osaka University Dental School, \\ 4-3-48 Nakanoshima, Kita-ku, Osaka, 530 Japan
}

(Received 31 January 1979; revised 4 June 1979)

Cell-free glucosyltransferase of Streptococcus mutans strain B13 (serotype $d$ ) exclusively synthesized water-insoluble glucan from sucrose. The insoluble glucan possessed strong glucan-associated glucosyltransferase activity even after extensive washing and lyophilization. Furthermore, cell-free glucosyltransferase became bound to heat-treated waterinsoluble glucan or to heat-treated $S$. mutans B13 cells grown in Todd Hewitt broth, and the resulting glucan and cells adhered to a glass surface in the presence of exogenous sucrose. No other water-insoluble glucans bound significant quantities of glucosyltransferase. Glucan synthesis by free or glucan-bound glucosyltransferase was stimulated by low concentrations ( 1 to $5 \mathrm{mg} \mathrm{ml}^{-1}$ ) of isomaltose or water-soluble dextrans of various molecular weights, but higher concentrations $\left(10 \mathrm{mg} \mathrm{ml}^{-1}\right)$ inhibited glucan synthesis. The glucan synthesized in the presence of primer dextrans exhibited a reduced ability to adhere to a glass surface. Certain sugars such as maltose and fructose significantly lowered the yield of insoluble glucans. Preincubation of glucosyltransferase with the low molecular weight dextran T10 increased subsequent binding to $S$. mutans B13 insoluble glucan, whereas preincubation with higher molecular weight dextrans significantly inhibited the glucosyltransferase binding.

\section{INTRODUCTION}

Streptococcus mutans is strongly implicated in the development of dental caries (Krasse \& Carlsson, 1970; Gibbons \& Van Houte, 1975 a; Hamada et al., 1978b). Two characteristic properties of the organism, namely its ability to adhere to surfaces and to form acids, could be associated with its ability to produce erosion on the tooth surface.

Adherence of $S$. mutans cells to smooth surfaces is mediated mainly by insoluble extracellular glucan synthesized from sucrose by the adhering cells (Gibbons \& Nygaard, 1968; Freedman \& Tanzer, 1974; Gibbons \& Van Houte, 1975b; Hamada, 1977; Slade, 1977). Streptococcus mutans grown in sucrose broth retains cell-associated glucosyltransferase (GTase; EC 2.4.1.5) whereas bacteria grown in glucose broth do not possess significant amounts of cell-associated GTase (Hamada \& Torii, 1978). Heat-treated S. mutans and cellfree water-insoluble glucans have been found to bind cell-free GTase, suggesting that the cellular binding sites for the GTase are the surface glucans (Hamada \& Torii, 1978). The adherence of $S$. mutans depends primarily on its ability to bind its own cell-free GTase (Hamada et al., $1978 a, c$ ).

In the present communication we describe the interactions between cell-free GTase of $S$. mutans and water-insoluble and water-soluble glucans of different origins. The effects of these interactions on de novo glucan synthesis and adherence to glass surfaces are also considered. 


\section{METHODS}

Organism. Streptococcus mutans strain B13 (serotype $d$ ) was supplied by Dr S. Edwardsson (University of Lund, Malmö, Sweden). Organisms were grown in Todd Hewitt broth at $37^{\circ} \mathrm{C}$ for $18 \mathrm{~h}$, centrifuged and washed with water. Cells were lyophilized and kept in the cold.

Preparation of cell-free GTase. The organism was grown at $37^{\circ} \mathrm{C}$ in TTY broth (Hamada \& Torii, 1978). Cell-free GTase was prepared from the culture medium by addition of solid $\left(\mathrm{NH}_{4}\right)_{2} \mathrm{SO}_{4}$ to yield a final concentration of $50 \%$ saturation. The precipitate was dissolved in $0.05 \mathrm{M}$-potassium phosphate buffer, $\mathrm{pH} 6.8$ (KPB) to $1 / 100$ of the original culture volume and dialysed extensively against KPB. No detectable fructosyltransferase activity was demonstrated as judged by the incorporation of radioactivity into polysaccharide from 1- $O$-( $\alpha$-D-glucopyranosyl) $\beta$-D-[U- $\left.{ }^{14} \mathrm{C}\right]$ fructofuranoside, that is, sucrose labelled in the fructosyl moiety (Hamada \& Torii, 1978). The glucan synthesized by this enzyme preparation from sucrose was almost exclusively insoluble in water. A single batch of enzyme preparation was used in this study.

Preparation of cell-free water-insoluble glucan. Cell-free GTase preparation $(10 \mathrm{ml})$ was incubated at $37^{\circ} \mathrm{C}$ for $18 \mathrm{~h}$ with $500 \mathrm{ml} 5 \%$ (w/v) sucrose in KPB. Merthiolate was added at a final concentration of $0.01 \%(\mathrm{w} / \mathrm{v})$ as a preservative. The resulting white precipitate was separated from the reaction mixture by centrifuging at $10000 \mathrm{~g}$ for $30 \mathrm{~min}$, washed twice with water $(250 \mathrm{ml}$ each) and lyophilized.

Assay of insoluble glucan synthesized by GTase associated with insoluble glucan and cells. Lyophilized glucans or cells were suspended in KPB at $5 \mathrm{mg} \mathrm{ml}^{-1}$. After ultrasonic dispersion, $400 \mu \mathrm{l}$ of the suspension was mixed with $500 \mu \mathrm{KPB}$ and $100 \mu 1\left[\mathrm{U}-{ }^{14} \mathrm{C}\right]$ sucrose solution (about $1 \cdot 1 \times 10^{5} \mathrm{~d}$.p.m.); this sucrose solution was prepared by mixing $40 \mu \mathrm{l}(4 \mu \mathrm{Ci})$ [U-14 $\mathrm{C}$ ]sucrose (New England Nuclear; specific activity $396 \mathrm{mCi}$ $\mathrm{mmol}^{-1}$ ) with $342 \mathrm{mg}$ sucrose (reagent grade) in $7.96 \mathrm{ml} \mathrm{KPB}$. The reaction mixture was incubated at $37^{\circ} \mathrm{C}$ for $18 \mathrm{~h}$. The cells or glucans were then collected by centrifugation and washed twice in $2.5 \mathrm{ml} \mathrm{KPB}$. The cell or glucan pellet was mixed with scintillation fluid and the radioactivity was counted in an Aloka model LSC-673 liquid scintillation spectrometer (Aloka, Tokyo, Japan) as described previously (Hamada \& Torii, 1978).

Assay of cell-bound glucan synthesized by cell-free GTase bound to heat-treated glucans or cells. Glucans or cells were heated in water at $10{ }^{\circ} \mathrm{C}$ for $10 \mathrm{~min}$ to inactivate 'intrinsic' GTase activity, then washed twice with water and lyophilized. Heated glucans or cells $(2 \mathrm{mg})$ were dispersed ultrasonically in $2 \mathrm{ml} \mathrm{KPB}$ and mixed with GTase $(20 \mu \mathrm{l})$. The mixtures were allowed to remain at $20^{\circ} \mathrm{C}$ for $10 \mathrm{~min}$; they were then centrifuged and the pellets were washed with KPB to remove unbound GTase. Glucan- or cell-bound glucan synthesis was then measured as described above.

Assay of insoluble glucan synthesis by cell-free GTase. The reaction mixture consisted of $20 \mu \mathrm{l}$ GTase preparation, $0.6 \mathrm{ml} 5 \%(\mathrm{w} / \mathrm{v})$ sucrose and KPB to $3.0 \mathrm{ml}$. Dextrans or other saccharides were added to the reaction mixture when necessary. Merthiolate was included at a final concentration of $0.01 \%(\mathrm{w} / \mathrm{v})$ as a preservative. The mixture was incubated at $37^{\circ} \mathrm{C}$ for $18 \mathrm{~h}$, and $A_{550}$ was measured with a Shimadzu Bausch $\&$ Lomb Spectronic 20 spectrophotometer. Under the conditions employed, the increase in $A_{550}$ was proportional to the GTase concentration.

Adherence of heat-treated insoluble glucans. Cell-free water-insoluble glucans $(1.0 \mathrm{mg} \mathrm{dry} w \mathrm{wt})$ which had been heated at $100{ }^{\circ} \mathrm{C}$ for $10 \mathrm{~min}$ were first incubated with $20 \mu \mathrm{l}$ GTase in $2.0 \mathrm{ml} \mathrm{KPB}$ in a glass tube $(10 \times 75 \mathrm{~mm})$. After $10 \mathrm{~min}$ at $20^{\circ} \mathrm{C}$, glucans were collected and washed with KPB by centrifugation to remove free GTase. Buffered sucrose $(2.4 \mathrm{ml})$ was added, and the tube was incubated at $30^{\circ}$ to the vertical for $18 \mathrm{~h}$. The tube was then rotated, and the unattached glucans were transferred into a second tube. Buffer $(2.4 \mathrm{ml} \mathrm{KPB})$ was added to the first tube, rotated, and the detached glucans were poured into a third tube. The glucans adhering in the first tube were suspended in $2.4 \mathrm{ml} \mathrm{KPB}$ ultrasonically. The percentage adherence was defined at $100 \times A_{550}$ (tube 1$) / A_{550}$ (tubes $1+2+3$ ).

Reagents and chemicals. Dextranase AD17 was partially purified from the culture medium of Spicaria violacea IFO 6120 (Hamada et al., 1975). Highly purified maltose and a coupling sugar preparation were kindly supplied by Hayashibara Biochemical Laboratories (Okayama, Japan). Coupling sugar was prepared from starch by the action of cyclodextrin glucosyltransferase from a strain of Bacillus megaterium (Okada \& Kitahata, 1975; Ikeda et al., 1978). The coupling sugar preparation (lot C770204D) used in this study contained fructose (Fru), glucose (Glc), sucrose (Glc-Fru), maltose [(Glc) $]$, maltosylfructose [(Glc) $)_{2}$-Fru], $(\mathrm{Glc})_{3},(\mathrm{Glc})_{3}-\mathrm{Fru}$, and $(\mathrm{Glc})_{4}$ and/or $(\mathrm{Glc})_{4}$-Fru in the ratios (by weight) $0 \cdot 3: 4 \cdot 7: 12 \cdot 1: 7 \cdot 0: 11 \cdot 0: 6 \cdot 3: 8 \cdot 0: 50 \cdot 6$. Other materials were obtained as follows: crystalline trypsin (Trypsilin, Mochida Pharmaceutical Co., Tokyo, Japan); pronase P (Kaken Kogyo Co., Tokyo, Japan); Todd Hewitt broth and dextrin (Difco); microcrystalline cellulose, laminarin, dextran T18, oyster glycogen, 2-deoxyglucose and isomaltose (Sigma); inulin and $\alpha$-methyl-D-glucoside (Wako Pure Chemicals, Osaka, Japan); rabbit liver glycogen (Nutritional Biochemicals Co., Cleveland, Ohio, U.S.A.); dextrans T10, T40, T250, T500 and T2000 (Pharmacia); 
Table 1. Streptococcus mutans B13 cell- and glucan-associated GTase activity and adherence

Glucan synthesis was measured by incorporation of radioactivity from [U- $\left.{ }^{14} \mathrm{C}\right]$ sucrose. Adherence to a glass surface was measured as cell or glucan adherence due to active de novo glucan synthesis in the presence of sucrose (see Methods).

$\begin{array}{lcc} & \begin{array}{c}{\left[{ }^{14} \text { C Glucan }\right.} \\ \text { synthesis } \\ \text { (d.p.m.) }\end{array} & \begin{array}{c}\text { Adherence } \\ \text { to a glass } \\ \text { surface } \\ (\%)\end{array} \\ \begin{array}{l}\text { Unheated* } \\ \text { Cells }\end{array} & 6500 & 89 \\ \text { Glucan } & 5800 & 62 \\ \text { Heated } & & \\ \text { Cells } & 179 & 7 \cdot 3 \\ \text { Glucan } & 154 & 5 \cdot 9 \\ \text { Heated plus cell-free GTase } \dagger & & \\ \text { Cells } & 3600 & 84 \\ \text { Glucan } & 3600 & 87\end{array}$

* Glucan synthesized by 'intrinsic' GTase bound to cells grown in Todd Hewitt broth or to cell-free water-insoluble glucans.

$\dagger$ Glucan synthesized by cell-free GTase bound to heat-treated cells or glucans.

dextran T15 (Meito Sangyo, Nagoya, Japan); dextran T66 (Nakarai Chemicals, Kyoto, Japan); starch (Merck, Darmstadt, Germany); amylopectin (Tokyo Kasei Co., Tokyo). All other chemicals were of reagent grade.

\section{RESULTS}

\section{Cell- and glucan-associated GTase activity and adherence}

Lyophilized cells of $S$. mutans B13 which had been grown in Todd Hewitt broth, and cellfree water-insoluble glucans synthesized by cell-free GTase from sucrose, possessed significant GTase activity as revealed by $\left[{ }^{14} \mathrm{C}\right]$ glucan synthesis from $\left[\mathrm{U}-{ }^{14} \mathrm{C}\right]$ sucrose (Table 1 ). New glucan synthesis permitted both the cells and the glucans to achieve marked adherence to glass surfaces in the presence of sucrose.

Heat-treatment $\left(100^{\circ} \mathrm{C}, 10 \mathrm{~min}\right)$ resulted in the complete loss of bound GTase activity. If the heated cells or glucans were incubated with cell-free GTase, they bound significant amounts of GTase and recovered the ability to synthesize $\left[{ }^{14} \mathrm{C}\right]$ glucan from $\left[\mathrm{U}-{ }^{14} \mathrm{C}\right]$ sucrose and to adhere to glass surfaces. The amounts of $\left[{ }^{14} \mathrm{C}\right]$ glucan synthesized by cells and glucans to which GTase had been bound were similar (Table 1).

No significant changes in the binding ability of GTase to water-insoluble glucans were observed after treatment with dextranase, trypsin, pronase or sodium dodecyl sulphate (results not shown) suggesting that contaminating protein was not responsible for binding.

\section{Binding of GTase to insoluble polysaccharides}

The abilities of various insoluble glucans and a fructan to bind GTase were compared (Table 2). No significant binding was detected with starch, amylopectin and dextrin which are primarily $(1 \rightarrow 4)-\alpha$ linked, or with $\beta$-glucans such as cellulose, inulin or laminarin. Only glucans from $S$. mutans B13 which are predominantly composed of $(1 \rightarrow 3)-\alpha$ linkages bound significant amounts of GTase and promoted $\left[{ }^{14} \mathrm{C}\right]$ glucan synthesis.

Inhibition of GTase binding by dextran

Preincubation $\left(20^{\circ} \mathrm{C}, 30 \mathrm{~min}\right)$ of low molecular weight dextran T10 with GTase enhanced the subsequent binding of the enzyme to the $S$. mutans insoluble glucans ( $2 \mathrm{mg}$ dry wt), whereas preincubation with high molecular weight dextran T500 inhibited binding of GTase, the inhibition being dependent on the dextran concentration. Low concentrations of 


\section{Table 2. Binding of cell-free GTase to insoluble polysaccharides}

Cell-free GTase $(20 \mu \mathrm{l})$ was added to the insoluble polysaccharide $(2 \mathrm{mg})$. The mixture was incubated at $20^{\circ} \mathrm{C}$ for $10 \mathrm{~min}$, then washed with buffer to remove unbound GTase and assayed for polysaccharide-associated GTase, as described in Methods.

Insoluble polysaccharide
B13 insoluble glucan
Starch
Amylopectin
Dextrin
Laminarin
Cellulose
Inulin

$\begin{array}{lc}\text { Linkage } & \begin{array}{c}\text { synthesis } \\ \text { (d.p.m.) }\end{array} \\ (1 \rightarrow 3)-\alpha \gg(1 \rightarrow 6)-\alpha \text { glucan } & 3586 \\ (1 \rightarrow 4)-\alpha \gg(1 \rightarrow 6)-\alpha \text { glucan } & 257 \\ (1 \rightarrow 4)-\alpha \gg(1 \rightarrow 6)-\alpha \text { glucan } & 485 \\ (1 \rightarrow 4)-\alpha \text { glucan } & 232 \\ (1 \rightarrow 3)-\beta \text { glucan } & 156 \\ (1 \rightarrow 4)-\beta \text { glucan } & 270 \\ (1 \rightarrow 2)-\beta \text { fructan } & 213\end{array}$

Table 3. Effect of soluble dextrans on the binding of GTase to the insoluble glucans of $S$. mutans $\mathrm{B} 13$

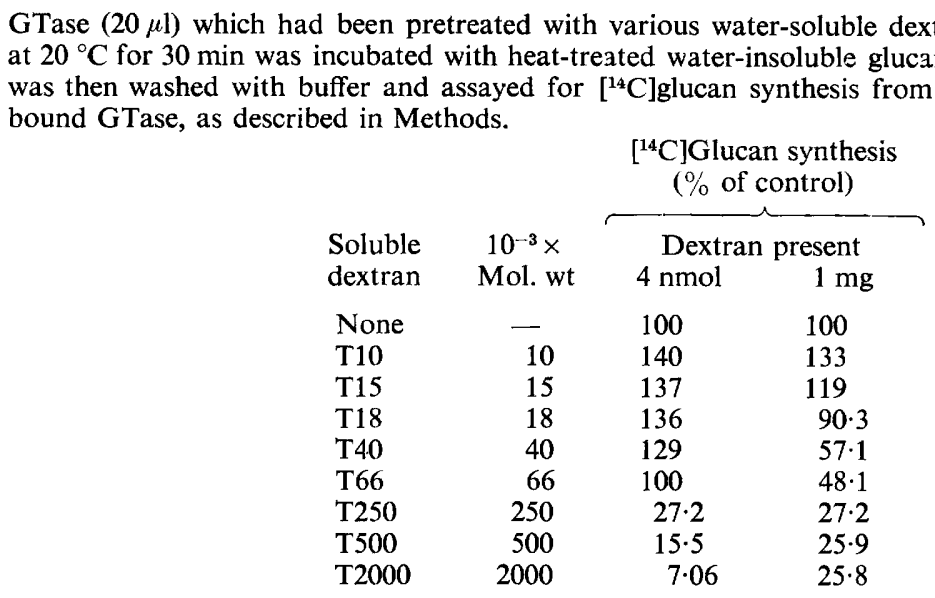

medium-sized dextrans such as T40 enhanced binding of GTase to insoluble glucans, whereas at higher concentrations binding was inhibited. Pretreatment with even low concentrations of high molecular weight dextrans (T500 or T2000) significantly inhibited subsequent GTase binding to insoluble glucans (Fig. 1 and Table 3).

Pretreatment with coupling sugar $(0.5$ to $1.0 \mathrm{mg})$ enhanced the GTase binding by 20 to $30 \%$ (results not shown). Other saccharides, such as glycogen (from liver and oyster), maltose, isomaltose, glucose and $\alpha$-methyl-D-glucoside, had no significant effect on GTase binding.

\section{Effect of soluble dextrans and various saccharides on insoluble glucan synthesis}

Insoluble glucan synthesis by cell-free GTase of $S$. mutans B 13 from sucrose $(1 \%$, w/v, final concentration) in the presence of various amounts of the soluble dextrans T10, T40, T250 or T2000 was followed spectrophotometrically (Fig. 2). The addition of dextran (irrespective of its molecular weight) up to concentrations of about 1 to $5 \mathrm{mg} \mathrm{ml}^{-1}$ resulted in an increased synthesis of insoluble glucan, after which a sharp decline in glucan production was observed. With dextran at $10 \mathrm{mg} \mathrm{ml}^{-1}$ or more, synthesis of insoluble glucan was markedly depressed and became negligible. Other soluble dextrans such as T18 and T500 gave similar results (not shown).

Among the mono-, di- and oligosaccharides examined, maltose, fructose and coupling 


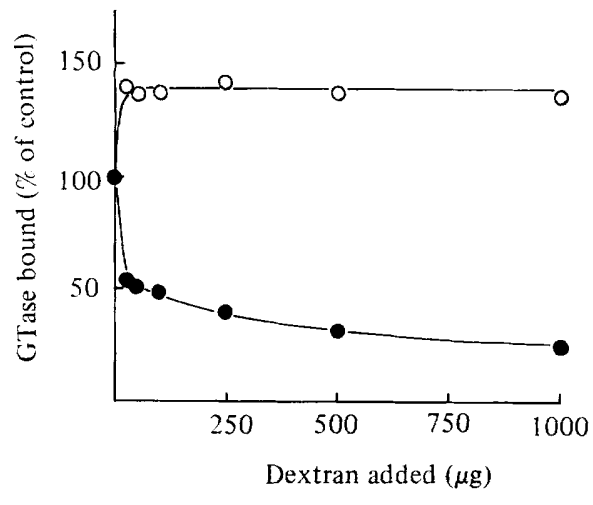

Fig. 1

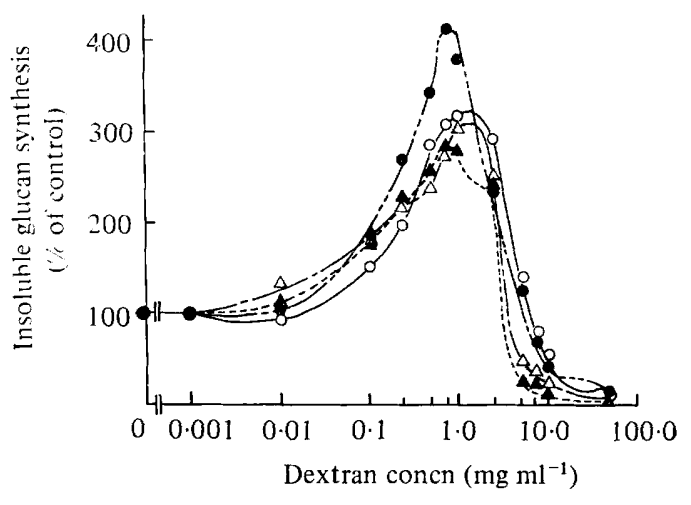

Fig. 2

Fig. 1. Effect of dextrans T10 (O) and T500 (O) on GTase binding of insoluble glucan. GTase $(20 \mu \mathrm{l})$ was preincubated with the indicated amounts of dextran, followed by incubation with insoluble glucan. Binding of GTase was measured as described in Methods and is expressed as a percentage of the control without added dextran. Each point is the average of three determinations.

Fig. 2. Effect of primer dextrans on insoluble glucan synthesis by cell-free GTase. Insoluble glucan synthesis in the presence of dextrans T10 (O), T40 ( $)$ ), T250 $(\triangle)$ and T2000 $(\Delta)$ was measured spectrophotometrically as described in Methods. Each point is the average of three determinations and is expressed as a percentage of the control without added dextran.

Table 4. Effect of various saccharides on insoluble glucan synthesis by cell-free GTase

Insoluble glucan synthesis was measured spectrophotometrically $\left(A_{550}\right)$. The control assay $\left(A_{550}=0 \cdot 310\right)$ had no added saccharide.

\begin{tabular}{|c|c|c|c|c|c|c|c|}
\hline \multirow[b]{3}{*}{ Saccharide } & \multicolumn{7}{|c|}{ Insoluble glucan synthesis ( $\%$ of control) } \\
\hline & \multicolumn{7}{|c|}{ Saccharide concn $\left(\mathrm{mg} \mathrm{ml}^{-1}\right)$} \\
\hline & $0 \cdot 01$ & $c \cdot 1$ & $1 \cdot 0$ & $5 \cdot 0$ & 10 & 30 & 50 \\
\hline Maltose & 88 & 88 & 70 & 28 & 18 & 9 & 8 \\
\hline Isomaltose & 184 & 165 & 118 & 56 & 31 & 19 & 19 \\
\hline Glucose & 86 & 96 & 88 & 82 & 75 & 60 & 34 \\
\hline 2-Deoxyglucose & 100 & 95 & 94 & 88 & 92 & 67 & 51 \\
\hline Fructose & 81 & 79 & 74 & 55 & 35 & 22 & 15 \\
\hline Raffinose & 84 & 89 & 91 & 83 & 79 & 80 & 73 \\
\hline Coupling sugar & 104 & 105 & 84 & 76 & 47 & 27 & 13 \\
\hline Inulin & 77 & 84 & 82 & 90 & 83 & 79 & 80 \\
\hline
\end{tabular}

sugar markedly inhibited synthesis of insoluble glucan (Table 4). Isomaltose at low concentrations (up to $1 \mathrm{mg} \mathrm{ml}^{-1}$ ) enhanced insoluble glucan production, but at higher concentrations it inhibited production, an effect similar to that shown by dextran (see Fig. 2). Glucose and 2-deoxyglucose at relatively high concentrations also inhibited insoluble glucan synthesis, but only a slight inhibition was observed on addition of raffinose or inulin (Table 4).

\section{Effect of soluble dextrans on de novo glucan synthesis and adherence due to glucan-associated GTase}

Activity of glucan-associated GTase was enhanced by the presence of soluble dextrans (up to $1 \mathrm{mg} \mathrm{ml}^{-1}$ ) regardless of the molecular weight of the dextran, whereas addition of higher concentrations of dextran ( 1 to $5 \mathrm{mg} \mathrm{ml}^{-1}$ ) inhibited de novo glucan-associated glucan synthesis (Fig. 3). The pattern of activation and subsequent inhibition of bound GTase by soluble dextrans was essentially similar to that of free GTase (see Fig. 2).

The effect of dextran T250 on adherence and insoluble glucan synthesis by heated glucan with bound cell-free GTase was examined. An inverse relationship between increased de novo glucan synthesis due to bound GTase and a decreased glucan adherence to glass surfaces was 


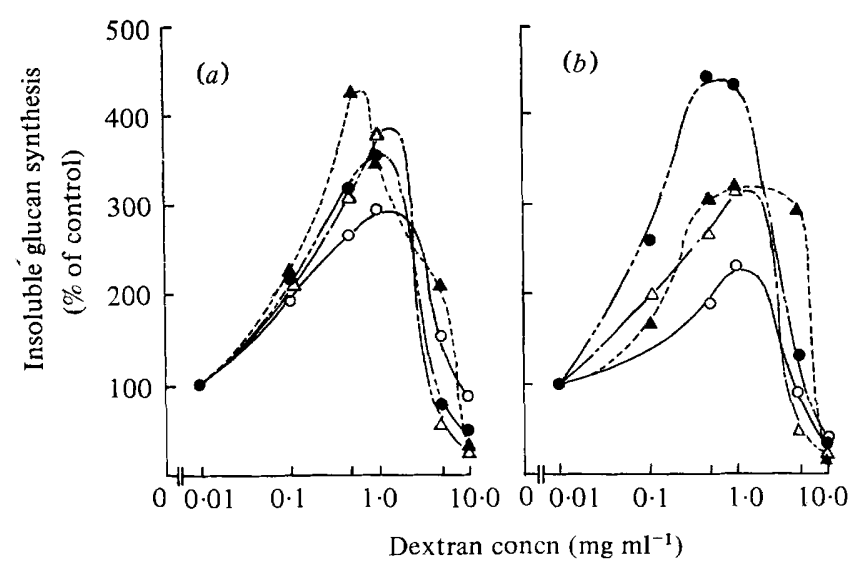

Fig. 3. Effect of primer dextrans on de novo glucan synthesis by glucan-associated GTase. Sucrose and various concentrations of dextrans T10 $(O)$, T40 (O), T250 $(\triangle)$ and T2000 $(\Delta)$ were added to unheated insoluble glucan $(a)$ or heated glucan with bound cell-free GTase $(b)$. Insoluble glucan synthesis was followed spectrophotometrically as described in Methods. Each point is the average of three determinations and is expressed as a percentage of the control without added dextran.

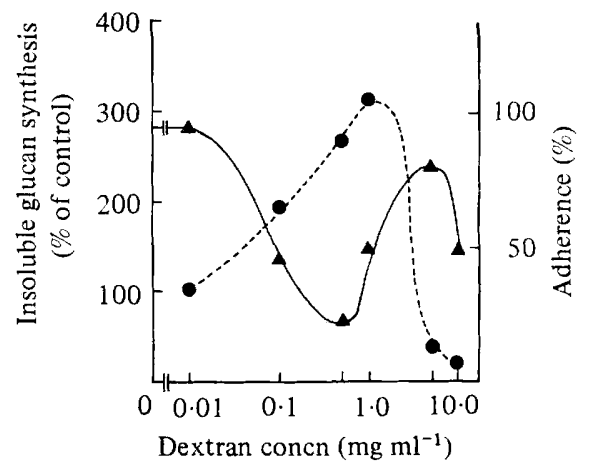

Fig. 4. Effect of dextran T250 concentration on de novo insoluble glucan synthesis ( $)$ and adherence to a glass surface $(\boldsymbol{\Lambda})$ of heated glucan with bound GTase in the presence of sucrose. Each determination was made in triplicate.

observed up to a concentration of $5 \mathrm{mg}$ dextran $\mathrm{ml}^{-1}$. Addition of higher concentrations of the dextran resulted in a sharp decline of de novo glucan formation (Fig. 4). Similar results were obtained with dextrans T10 and T2000 (results not shown).

\section{DISCUSSION}

The crude GTase preparation of $S$. mutans B13 (serotype $d$ ) produced exclusively waterinsoluble, adherent glucan from sucrose and possessed no detectable fructosyltransferase activity as revealed by our assay method (Hamada \& Torii, 1978). This system can therefore conveniently be used for studying the interaction of GTase with glucan.

We have found that cell-free GTase of $S$. mutans has a strong affinity for sucrose-grown cells and the insoluble glucan produced by GTase from sucrose, indicating that cell-surface glucan may be a binding site for GTase (Table 1; Hamada \& Torii, 1978). The nature of the GTase binding site is not known and remains to be elucidated. However, the fact that, among various glucans tested, only $S$. mutans insoluble glucan significantly binds GTase (Table 2) suggests that specific glucosidic linkages may be responsible for GTase binding. 
Furthermore, pretreatment of the glucan with dextranase did not alter the GTase binding capacity, indicating that terminal $(1 \rightarrow 6)-\alpha$ glucosidic linkages might not be involved in the enzyme binding. The physical nature of insoluble glucan, which is mainly composed of $(1 \rightarrow 3)-\alpha$ glucosidic linkages, may contribute to the effective binding of GTase.

Although addition of dextran T10 (mol. wt 10000) produced an increase in GTase binding to the insoluble glucans (Fig. 1), the addition of larger dextrans to the reaction mixture resulted in an increasing inhibition of GTase binding concomitant with the increase in molecular weight of the dextran (Fig. 1, Table 3).

Commercially available dextrans from Leuconostoc mesenteroides contain a single reducing end and multiple non-reducing ends (Germaine \& Schachtele, 1976; Walker, 1978). If non-reducing ends are responsible for the inhibition of GTase binding to the insoluble glucan, inhibition of glucan synthesis should be similar when compared on a weight basis. The results shown in Table 3 do not support this idea. Similarly, reducing ends do not appear to be responsible for the inhibition of GTase binding because the addition of equimolar dextrans resulted in various degrees of inhibition. These findings suggest that the whole dextran molecule is involved in inhibition of GTase binding to insoluble glucans and the inhibition efficiency depends on the molecular weight (i.e. chain length) of the dextran employed. On the other hand, low molecular weight dextran T10 might form a complex with GTase resulting in increased binding of GTase to insoluble glucan. The dextran molecule involved in the complex may act as a binder between GTase and insoluble glucan or act as an internal primer of GTase after the GTase has bound directly to the glucan.

In contrast to the present results, Kuramitsu \& Ingersoll (1978) have reported that the interactions of GTase fractions of $S$. mutans GS5 (serotype $c$ ) with cell surface glucan molecules were strongly inhibited by the addition of dextran T10 as well as T2000.

It has been reported that commercial dextran preparations with various molecular weights inhibited synthesis of insoluble glucan by $S$. mutans GTase from sucrose (Gibbons \& Nygaard, 1968; Gibbons \& Keyes, 1969; Ciardi et al., 1977). However, the present investigation (Figs 2 and 3) revealed that dextrans at low concentrations (up to about $5 \mathrm{mg} \mathrm{ml}^{-1}$ ), irrespective of their molecular weight, stimulated insoluble glucan synthesis; at higher concentrations of dextrans the synthesis of insoluble glucan was almost completely inhibited. Similar findings have been reported recently by others (Newbrun et al., 1977; Robyt \& Corrigan, 1977). The addition of higher concentrations (about $5 \mathrm{mg} \mathrm{ml}^{-1}$ ) of exogenous dextran is required in order to inhibit the synthesis of insoluble glucan by S. mutans GTase whether it is in a free state (Fig. 2) or in a glucan-bound state (Fig. 3). This observation does not agree with the previous finding that addition of only $0.01 \%$ dextran inhibited the synthesis of insoluble glucan by $S$. mutans GS5 GTase (Gibbons \& Keyes, 1969).

The stimulation of GTase by dextran can be explained by the primer effect of dextran on GTase, which has been described by several investigators (McCabe \& Smith, 1973, 1978; Germaine et al., 1974; Kuramitsu, 1975). Equal weights of dextrans with different molecular weights showed similar priming abilities in de novo glucan synthesis. This stimulation is similar to that reported previously by Germaine \& Schachtele (1976). On the other hand, Robyt \& Corrigan (1977) have claimed that the activation of GTase of $S$. mutans strain OMZ176 by dextrans is not due to primer reactions, but must be by an alternative mechanism.

Newly synthesized glucan, formed under the stimulation of exogenous dextran, possessed a decreased ability to adhere to a smooth glass surface. The exogenous dextran is considered to act as an acceptor and hence to be covalently bound to the new glucan (Ebert $\&$ Brosche, 1967; Germaine et al., 1974). The increase in the incorporation of primer dextran into the glucan results in a change of the physico-chemical properties of the newly synthesized glucan, and the resultant glucan appears gelatinous, which may account for its decreased adherence. In this connection, McCabe \& Smith (1973) and Montiville et al. (1977) reported 
that insoluble glucan synthesis by $S$. mutans GTase can be shifted to soluble glucan synthesis by the addition of dextrans. Gibbons \& Keyes (1969) observed that addition of low molecular weight dextran to the diets of hamsters produced a significant reduction in dental plaque formation and caries, whereas Shaw (1972) reported no alteration in caries activity in rats under similar conditions. These conflicting results may reflect the dual effects of dextran on the GTase activity, as described above.

It has been reported that low molecular weight glucosyl acceptors such as maltose, isomaltose and $\alpha$-methyl-D-glucoside increased the reaction rate of GTase-dependent insoluble glucan synthesis but inhibited the rate of dextran synthesis (Koepsell et al., 1953; Bovey 1959; Figures \& Edwards, 1976; Walker, 1978). However, we have found that isomaltose at lower concentrations, like dextrans, stimulated GTase which, in turn, resulted in an increase in the synthesis of insoluble glucan (Table 4); at higher concentrations, the addition of isomaltose markedly reduced the amount of glucan formed. Many other sugars examined, especially maltose, did not stimulate, but inhibited GTase, as was reported previously by other investigators (Gibbons \& Nygaard, 1968; Knuttila \& Mäkinen, 1972; Newbrun et al., 1977; Balekjian et al., 1977).

We thank Dr Rosemary Linzer for assistance with the English version of the manuscript. Our thanks are also due to Dr S. Kotani for his continuing interest and encouragement.

This paper is dedicated to Dr Hutton D. Slade on the occasion of his retirement from Northwestern University, Chicago, Ill., U.S.A.

\section{REFERENCES}

Balekjian, A. Y., Longton, R. W., Cole, J. S. \& GuIDRY, M. S. (1977). The effect of disaccharides on the plaque-forming potential of Streptococcus mutans. Journal of Dentcil Research 56, 1359-1363.

BOVEY, F. A. (1959). Enzymatic polymerization III. The influence of a glucosyl acceptor, methyl $\alpha$ D-glucoside, on the molecular weight and kinetics of formation of dextran. Journal of Polymer Science 35, 191-204.

Ciardi, J. E., Beaman, A. J. \& Wittenberger, C. L. (1977). Purification, resolution and interaction of the glucosyltransferases of Streptococcus mutans 6715. Infection and Immunity 18, 237-246.

Ebert, K. H. \& Brosche, M. (1967). Origin of branches in native dextrans. Biopolymers 5, 123130.

Figures, W. R. \& Edwards, J. R. (1976). $\alpha$-DGlucopyranosyl fluoride as a D-glucopyranosyl donor for a glycosyltransferase complex from Streptococcus mutans FA1. Carbohydrate Research 48, 245-253.

Freedman, M. L. \& Tanzer, J. M. (1974). Dissociation of plaque formation from glucan-induced aggregation in mutants of Streptococcus mutans. Infection and Immunity 10, 189-196.

Germaine, G. R. \& Schachtele, C. F. (1976). Streptococcus mutans dextransucrase: mode of interaction with high-molecular-weight dextran and role in cellular aggregation. Infection and Immunity 13, 365-372.

Germaine, G. R., Chludzinski, A. M. \& SchachTELE, C. F. (1974). Streptococcus mutans dextransucrase: requirement for primer dextran. Journal of Bacteriology 120, 287-294.

Gibbons, R. J. \& Keyes, P. H. (1969). Inhibition of insoluble dextran synthesis, plaque formation and dental caries in hamsters by low molecular weight dextran. Archives of Oral Biology 14, 721-724.

GibBons, R. J. \& NyGAARD, M. (1968). Synthesis of insoluble dextran and its significance in the formation of gelatinous deposits by plaqueforming streptococci. Archives of Oral Biology 13, 1249-1262.

Gibbons, R. J. \& Van Houte, J. (1975a). Dental caries. Annual Review of Medicine 26, 121-136.

Gibbons, R. J. \& VAN Houte, J. (1975b). Bacterial adherence in oral microbial ecology. Annual Review of Microbiology 29, 19-44.

Hamada, S. (1977). New glucan synthesis as a prerequisite for adherence of Streptococcus mutans to smooth glass surfaces. Microbios Letters 5, 141146.

Hamada, S. \& Torit, M. (1978). Effect of sucrose in culture media on the location of glucosyltransferase of Streptococcus mutans and cell adherence to glass surfaces. Infection and Immunity 20, 592-599.

Hamada, S., Mizuno, J., Murayama, Y., Ooshima, T., Masuda, N. \& Sobue, S. (1975). Effect of dextranase on the extracellular polysaccharide synthesis of Streptococcus mutans: chemical and scanning electron microscopy studies. Infection and Immunity 12, 1415-1425.

Hamada, S., Kobayashi, Y. \& Slade, H. D. (1978a). Cell-bound glucan synthesis and subsequent adherence of oral streptococci due to the binding of extracellular glucosyltransferase to the streptococcal cell surface. Microbiology and Immunology 22, 279-282.

Hamada, S., Ooshima, T., ToriI, M., Imanishi, H., 
Masuda, N., Sobue, S. \& Kotani, S. (1978b). Dental caries induction in experimental animals by clinical strains of Streptococcus mutans isolated from Japanese children. Microbiology and $\mathrm{Im}^{-}$ munology 22, 301-314.

Hamada, S., TAI, S. \& Slade, H. D. (1978 ${ }^{\circ}$ ). Binding of glucosyltransferase and glucan synthesis by Streptococcus mutans and other bacteria. Infection and Immunity 21, 213-220.

Ikeda, T., Shiota, T., McGhee, J. R., Otake, S., Michalek, S. M., Ochiai, K., Hirasawa, M. \& Sugimoto, K. (1978). Virulence of Streptococcus mutans: composition of the effects of a coupling sugar and sucrose on certain metabolic activities and cariogenicity. Infection and Immunity 19, 477-480.

KNutTILA, M. L. E. \& MÄKINEN, K. K. (1972). Effect of maltose on polysaccharide synthesis by a cariogenic Streptococcus. Journal of Dental Research 51, 674.

Koepsell, H. J., Tsuchiya, H. M., Hellman, N. N., Kazenko, A., Hoffman, C. A., Sharpe, E. S. \& JACKSON, R. W. (1953). Enzymatic synthesis of dextran. Acceptor specificity and chain initiation. Journal of Biological Chemistry 200, 793-801.

Krasse, B. \& Carlsson, J. (1970). Various types of streptococci and experimental caries in hamsters. Archives of Oral Biology 15, 25-32.

Kuramitsu, H. K. (1975). Characterization of extracellular glucosyltransferase activity of Streptococcus mutans. Infection and Immunity 12, 738-749.

Kuramitsu, H. K. \& Ingersoll, L. (1978). Interaction of glucosyltransferases with the cell surface of Streptococcus mutans. Infection and Immunity 20, 652-659.
MCC ABE, M. M. \& SMith, E. E. (1973). Origin of the cell-associated dextransucrase of Streptococcus mutans. Infection and Immunity 7, 829-838.

MCCABE, M. M. \& SMith, E. E. (1978). The dextran acceptor reaction of dextransucrase from Streptococcus mutans K1-R. Carbohydrate Research 63, 223-239.

Montiville, T. J., Cooney, C. L. \& Sinskey, A. J. (1977). Distribution of dextransucrase in Streptococcus mutans and observations on the effect of soluble dextran on dextransucrase activities. Infection and Immunity 18, 629-635.

Newbrun, E., Finzen, F. \& Sharma, M. (1977). Inhibition of adherence of Streptococcus mutans to glass surfaces. Caries Research 11, 153-159.

Okada, S. \& Kitahata, S. (1975). Preparation and some properties of sucrose bound syrup. Journal of the Japanese Food Industry 22, 6-10.

Robyt, J.F. \& Corrigan, A. J. (1977). The mechanism of dextransucrase action. Archives of Biochemistry and Biophysics 183, 726-731.

SHAw, J. (1972). Ineffectiveness of low molecular weight dextrans in the prevention of experimental dental caries in mutant albino rats. Archives of Oral Biology 17, 363-366.

Slade, H. D. (1977). Cell surface antigenic polymers of Streptococcus mutans and their role in adherence of the microorganism in vitro. In Microbiology1977, pp. 411-416. Edited by D. Schlessinger. Washington, D.C.: American Society for Microbiology.

WALKeR, G. J. (1978). Dextrans. In International Review of Biochemistry, Biochemistry of Carbohydrates II, 16, 75-126. Edited by D. J. Manners. Baltimore: University Park Press. 